\title{
Asymmetric Baylis-Hillman reaction catalyzed by pyrrolidine based organocatalyst
}

\author{
Madhavi S. Menkudle ${ }^{1}$. Shrikant S. Pendalwar ${ }^{1} \cdot$ Santosh V. Goswami ${ }^{1} \cdot$ Wamanrao N. Jadhav ${ }^{1}$. \\ Sudhakar R. Bhusare ${ }^{1}$
}

Received: 24 January 2020 / Accepted: 12 March 2020 / Published online: 17 March 2020

(c) Springer Nature Switzerland AG 2020

\begin{abstract}
An asymmetric Baylis-Hillman reaction protocol has been developed using a chiral pyrrolidine based organocatalyst. The catalytic loading works well with a wide range of aromatic aldehydes to afford the corresponding $\beta$-hydroxy acrylate with high enantioselectivity up to $100 \%$ with excellent yields. The organocatalyst shows excellent enantioselectivity with $10 \mathrm{~mol} \%$ of catalytic loading at room temperature condition.
\end{abstract}

Graphic abstract<smiles>[R]c1ccc(C=O)cc1</smiles>

4a-j<smiles>C=CC(=O)OC</smiles>

5

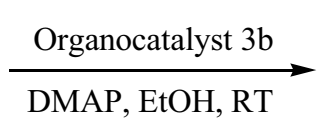

$\mathrm{R}$<smiles>[R]c1ccc(C(O)C(=C)C(=O)OC)cc1</smiles>

6a-j

Keywords Enantioselectivity · Organocatalysis · Baylis-Hillman reaction · Asymmetric synthesis

\section{Introduction}

The Baylis-Hillman reaction is an important carbon-carbon bond formation process and has drawn considerable attention over the past few years [1-5]. The condensation reaction of an acrylate or otherwise activated terminal olefin with an aldehyde, provides a simple and appropriate route to a very useful class of functionalized olefins. This reaction involves three components, an activated alkene, electrophile and nucleophilic catalyst respectively. DABCO [6], DMAP [7], DBU [8], phosphines [9], chalcogen species [10] and imidazole [11] are frequently used as Lewis bases in this reaction as catalysts. Besides, Lewis acid accelerated reactions were also reported, such as $\mathrm{TiCl}_{4}$ [12], $\mathrm{Et}_{2} \mathrm{All}$ [13] and $\mathrm{BF}_{3}$ [14] Not only variations of catalysts and solvent [15], but also modifications such as the use of high pressure [16], microwave [17] and ultrasound [18] have given some promising results. Conversely, the solvent also has a significant effect on the reaction rate [19] and even different salt effects [20] on the reaction rate. This prompted us to develop a new series of pyrrolidine based catalysts to replace the Lewis bases in the traditional Baylis-Hillman reaction. Thus in continuation of our work in enantioselective organocatalytic synthesis [21-23], herein we report an efficient method for highly enantioselective Baylis-Hillman reaction using a chiral pyrrolidine based organocatalyst under ambient temperature via hydrogenbonding interaction.

Sudhakar R. Bhusare, bhusare71@yahoo.com | 'Department of Chemistry, Dnyanopasak College, Parbhani, Maharashtra 431401, India. 


\section{Results and discussion}

Catalysts $(\mathbf{3 a} \mathbf{3} \mathbf{3} \mathbf{c})$ were prepared from the $\mathrm{N}-\mathrm{Boc}$ protected L-proline and the corresponding amines as morpholine, 2,4-dinitro aniline and 2-amino pyridine according to the known synthetic routes (Scheme 1).

These organocatalysts were purified by column chromatography and characterized by ${ }^{1} \mathrm{H} N M R,{ }^{13} \mathrm{C} N M R$, mass, IR and Chiral HPLC. The procedures for preparing pyrrolidine based chiral organocatalysts $\mathbf{3 a - 3 c}$ were outlined in Scheme 1. First, commercially available N-Boc-L-proline reacted with cyanuric chloride in ethyl acetate solvent and triethylamine as a base, at the $0{ }^{\circ} \mathrm{C}$. After stirring for half hour amine was added to it. The reaction mixture was left stirring for additional $60 \mathrm{~min}$. The solid from the reaction mixture was then filtered and washed with small amount of ethyl acetate. The filtrate was washed with $1 \times 20 \mathrm{ml}$

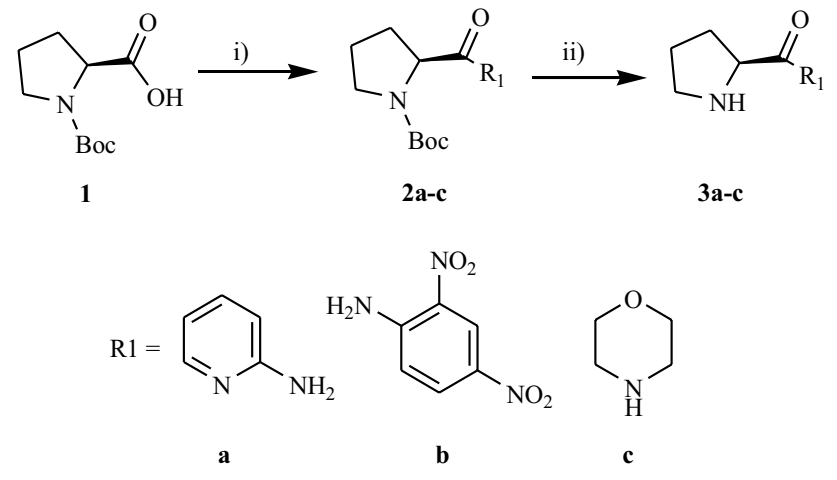

Scheme1 Reagent and conditions: (i) Cyanuric chloride, Ethyl acetate, $\mathrm{Et}_{3} \mathrm{~N}, \mathrm{R}_{1}-\mathrm{NH}_{2}$, r.t.; (ii) TFA, DCM, $0^{\circ} \mathrm{C}$ of $1 \mathrm{M} \mathrm{NaOH}$ solution and separated. Then the separated organic layer was extracted with $2 \times 20 \mathrm{ml}$ distilled water, organic layer separated and dried over $\mathrm{Na}_{2} \mathrm{SO}_{4}$. The obtained organic phase was evaporated on vacuo. The resulting solid was then digested in ether to get crude product. After it, the $\mathrm{N}-\mathrm{Boc}$ protecting group was removed to get pyrrolidine based chiral organocatalysts $\mathbf{3 a}-\mathbf{3 c}$.

In the initial studies, set of experiments were performed by the model reaction of $p$-nitrobenzaldehyde $\mathbf{4 a}$ with methyl acrylate $\mathbf{5}$ using various solvent in the presence of organocatalysts $(\mathbf{3 a}-\mathbf{3 c})$ to give product methyl 2-(hydroxy(4-nitrophenyl)methyl)acrylate $\mathbf{6 a}$. The results obtained are shown in Table 1 . In presence of organocatalyst $3 \mathrm{a}$, the reaction took $42 \mathrm{~h}$ to complete with $46 \%$ isolated yield in solvent DCM (Entry 1, Table 1). The same reaction with organocatalyst $\mathbf{3 b}$ in DCM offered a yield of $62 \%$ in $30 \mathrm{~h}$ (Entry 2, Table 1). When the reaction was carried out in DCM in presence of organocatalyst 3c, we obtained desired product in $36 \mathrm{~h}$ with $50 \%$ yield (Entry 3, Table 1 ). However, the affordable result was obtained when the reaction was carried out in ethanol using organocatalyst $3 \mathrm{~b}$; good yield of $72 \%$ was obtained with $74 \%$ ee in $16 \mathrm{~h}$ (Entry 4, Table 1). So further we studied with organocatalyst $\mathbf{3 b}$ in different solvent such as toluene, DMF and water respectively (Entry 5-7 respectively, Table 1 ). From this study, we have decided to perform next optimization in solvent ethanol with organocatalyst $\mathbf{3 b}$.

Next, we studied optimization of reaction using ethanol as solvent and varying the organocatalyst amount. When the catalyst loading was raised from $12 \mathrm{~mol} \%$ and $15 \mathrm{~mol} \%$, there was no significant enhancement in the results (Entry $8-9$, Table 1 ). In absence of catalyst, the
Table 1 Effect of catalyst and solvent on Baylis-Hillman reaction

\begin{tabular}{lllllll}
\hline Entry & Catalyst & Solvent & mol\% & Time (h) & Yield $^{\text {a }}$ () & $e e^{\text {b }}$ \\
\hline 1 & 3a & DCM & 10 & 42 & 46 & 44 \\
2 & 3b & DCM & 10 & 30 & 62 & 59 \\
3 & 3c & DCM & 10 & 36 & 50 & 52 \\
$\mathbf{4}$ & 3b & EtOH & 10 & 16 & $\mathbf{7 2}$ & $\mathbf{7 4}$ \\
5 & 3b & Toluene & 10 & 28 & 54 & 46 \\
6 & 3b & DMF & 10 & 30 & 48 & 52 \\
7 & 3b & Water & 10 & 48 & 42 & 38 \\
8 & 3b & EtOH & 12 & 18 & 72 & 64 \\
9 & 3b & EtOH & 15 & 17 & 68 & 64 \\
10 & 3b & EtOH & - & 48 & 40 & - \\
\hline
\end{tabular}

Conditions: p-Nitrobenzaldehyde $(1.0 \mathrm{mmol})$, methyl acrylate $(1.2 \mathrm{mmol})$, solvent $(10 \mathrm{ml})$ and organocatalyst (mol\%) at RT

Bold indicates selected reaction conditions

asolated yields

${ }^{\text {b}}$ Determined by chiral HPLC 
Table 2 The optimization of base on Baylis-Hillman reaction

\begin{tabular}{llclll}
\hline Entry & Base & mol\% & Time (h) & Yield $^{\mathrm{a}}(\%)$ & $\mathrm{ee}^{\mathrm{b}}$ \\
\hline 1 & Pyridine & 5 & 24 & 66 & 56 \\
2 & Triethylamine & 5 & 22 & 70 & 78 \\
3 & Piperidine & 5 & 26 & 48 & 52 \\
4 & DMAP & 5 & 18 & 75 & 80 \\
5 & Morpholine & 5 & 36 & 42 & 54 \\
$\mathbf{6}$ & DMAP & $\mathbf{1 0}$ & $\mathbf{1 4}$ & $\mathbf{8 9}$ & $\mathbf{9 8}$ \\
7 & DMAP & 12 & 14 & 85 & 88 \\
\hline
\end{tabular}

Conditions: p-Nitrobenzaldehyde $(1.0 \mathrm{mmol})$, methyl acrylate $(1.2 \mathrm{mmol})$, ethanol $(10 \mathrm{ml})$, organocatalyst $3 \mathrm{~b}(10 \mathrm{~mol} \%)$ and base (mol\%) at RT

Bold indicates selected reaction conditions

${ }^{\text {a }}$ ssolated yields

${ }^{\text {b}}$ Determined by chiral HPLC

reaction affording low product yield with extended reaction time (Entry 10, Table 1).

Further we studied the effect of organic bases on the reaction as shown in Table 2 . The use of base, such as pyridine (5 mol\%) as an additive gave the corresponding product $6 \mathrm{a}$ in $66 \%$ yield in $24 \mathrm{~h}$ with $56 \%$ ee (Entry 1, Table 2). With base triethylamine, the reaction affords $70 \%$ yield in a $22 \mathrm{~h}$ and $78 \%$ ee (Entry 2, Table 2). The piperidine as the base offers $48 \%$ product yield in $26 \mathrm{~h}$ with $52 \%$ ee (Entry 3, Table 2). DMAP appears to be suitable base for the Baylis-Hillman reaction as the best results were obtained with this ( $75 \%$ yield and $80 \%$ ee), (Entry 4 , Table 2 ). Using morpholine as a base, the reaction offered low yield with low enantioselectivity (Entry 5, Table 2). Thus, DMAP has chosen the best base for Baylis-Hillman reaction. In order to study the effect of base amount for the better productivity, we carried out there action at different mol\% of DMAP. At $10 \mathrm{~mol} \%$ of DMAP, the superior result was observed in order to yield and enantioselectivity. The reaction completed in $14 \mathrm{~h}$ with higher $89 \%$ yield and $98 \%$ enantioselectivity (Entry 6, Table 2). Further increase in base amount up to $12 \mathrm{~mol} \%$, no improvement was observed with correspond to yield and enantioselectivity (Entry 7, Table 2).

On exploring present method, the other aromatic aldehydes reacted with methyl acrylate smoothly in the presence of DMAP under the optimized conditions to give the corresponding Baylis-Hillman adducts in good to moderate yields (Scheme 2). The results are summarized in Table 3. The nature of the substituent on the phenyl ring has a profound effect. When substituent with fluoro, nitro functional group were used as the substrate, the Baylis-Hillman reaction was finished within 14-15 h, which
Scheme 2 Baylis-Hillman Reaction Catalyzed by Organocatalyst

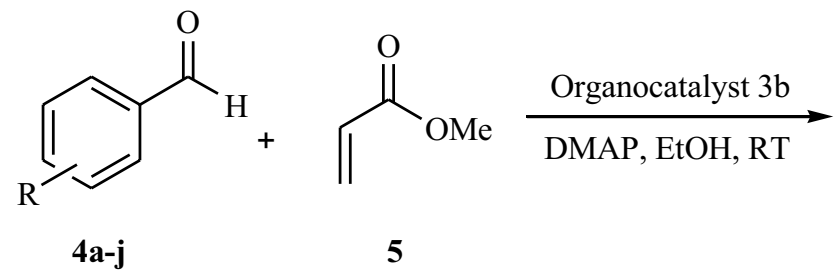<smiles>[R][X]c1ccc(C(O)C(=C)C(=O)OC)cc1</smiles>

6a-j
Table 3 Synthesis of BaylisHillman adducts

\begin{tabular}{lllllrl}
\hline Entry & $\mathrm{R}$ & Time $(\mathrm{h})$ & Product & Yield $^{\mathrm{a}}(\%)$ & $\mathrm{ee}$ & $(\mathrm{a})_{D}^{\mathrm{c}}$ \\
\hline 1 & $4-\mathrm{NO}_{2}$ & 14 & $6 \mathrm{a}$ & 89 & 98 & -15.8 \\
2 & $4-\mathrm{OH}$ & 15 & $6 \mathrm{~b}$ & 80 & 100 & -11.3 \\
3 & $1-\mathrm{Naphthaldehyde}$ & 16 & $6 \mathrm{c}$ & 76 & 88 & -51.5 \\
4 & $4-\mathrm{Cl}$ & 14.5 & $6 \mathrm{~d}$ & 82 & 86 & -10.1 \\
5 & $4-\mathrm{F}$ & 14 & $6 \mathrm{e}$ & 90 & 96 & -56.7 \\
6 & $4-\mathrm{OCH}_{3}$ & 17 & $6 \mathrm{f}$ & 84 & 87 & -13.7 \\
7 & $3,4-\mathrm{OCH}_{3}$ & 19 & $6 \mathrm{~g}$ & 84 & 85 & -26.2 \\
8 & $3-\mathrm{OH}$ & 15 & $6 \mathrm{~h}$ & 80 & 97 & -49.2 \\
9 & $\mathrm{H}$ & 18 & $6 \mathrm{i}$ & 75 & 86 & -50.4 \\
10 & $3-\mathrm{NO}_{2}$ & 15 & $6 \mathrm{j}$ & 87 & 90 & -61.3 \\
\hline
\end{tabular}

Conditions: Aromatic aldehyde $(1.0 \mathrm{mmol})$, methyl acrylate $(1.2 \mathrm{mmol})$, ethanol $(10 \mathrm{ml})$, organocatalyst $3 \mathrm{~b}$ (10 mol\%) and DMAP (10 mol\%) at RT

asolated yields

${ }^{\text {b}}$ Determined by chiral HPLC 
should be attributed to the strong electron-withdrawing ability of functional group on phenyl ring, whereas an electron-donating substituent lowered the yield and increased the reaction time.

\section{Experimental}

All solvents were employed as commercial anhydrous grade without further purification. Optical rotations were measured on a Polax-2L digital polarimeter. ${ }^{1} \mathrm{H}$ and ${ }^{13} \mathrm{C}$ NMR spectra were recorded on a Bruker $300 \mathrm{MHz}$ spectrometer in $\mathrm{CDCl}_{3}$ solvent. Mass spectra were taken on PE SCIEX, API-2000 Analyst (1.4.2). Enantiomeric purity is determined on Waters alliance 2996 separation module HPLC Systems.

\section{General procedure for the Baylis-Hillman reaction}

To the stirred mixture of aromatic aldehyde $(1.0 \mathrm{mmol})$ and methyl acrylate $(1.2 \mathrm{mmol}$ ) were added DMAP (10 mol\%) and organocatalyst (10 mol\%) in ethanol solvent. Initially the homogeneous reaction mixture was stirred in ice bath for $1 \mathrm{~h}$. Then the reaction mixture was stirred at room temperature for appropriate time (Table 3). The progress of the reaction was monitored by thin layer chromatography. After completion of the reaction as directed by TLC, the solvent was evaporated and dichloromethane was added. Washed with dil $\mathrm{HCl}$ and dried over anhydrous sodium bisulphate, filtrated, and then concentrated to vacuo. The resulting crude product was further purified by column chromatography using silica gel (mesh 80-100), and ethyl acetate and Hexane as eluent to give the pure product as Baylis-Hillman adduct.

\subsection{Methyl 2-(hydroxy(4-hydroxyphenyl) methyl) acrylate (6b)}

Optical rotation [a]D: - 11.3 (c 0.5 , ethyl acetate); IR: 858 , $1112,1598,1667,2924,3168 \mathrm{~cm}^{-1}$; ${ }^{1} \mathrm{H}$ NMR $(300 \mathrm{MHz}$, $\mathrm{CDCl} 3): \delta 7.81-7.95(\mathrm{~m}, 2 \mathrm{H}), 6.92-7.10(\mathrm{~m}, 2 \mathrm{H}), 6.35(\mathrm{~m}, 1 \mathrm{H})$, $5.90(\mathrm{~d}, 1 \mathrm{H}), 5.58(\mathrm{~s}, 1 \mathrm{H}), 4.80(\mathrm{~s}, 1 \mathrm{H}), 3.70(\mathrm{~s}, 3 \mathrm{H}), 2.18(\mathrm{~s}$, $1 \mathrm{H}, \mathrm{OH}) ;{ }^{13} \mathrm{C}-\mathrm{NMR}\left(75 \mathrm{MHz}, \mathrm{CDCl}_{3}\right): \delta 58.42,77.33,115.91$, 124.34, 132.35, 138.26, 144.82, 161.13, 190.06; MS: m/z 208 expected and m/z 211.20 obtained (M-); HPLC: 100\% ee. [Determined by chiral-pack OD-H $(250 \times 4.6 \mathrm{~mm}) 5 \mu \mathrm{m}$, mobile phase: $n$-Hexane: Ethanol: Diethylamine (95:5:0.1), Flow rate $1.0 \mathrm{~mL} / \mathrm{min}, \chi=280 \mathrm{~nm}$; $\mathrm{tR}$ (major) $=10.48 \mathrm{~min}$, run time $=30 \mathrm{~min}$, column temperature $=$ Ambient $]$.

\subsection{Methyl 2-(hydroxy(3-hydroxyphenyl) methyl) acrylate $(6 \mathrm{~h})$}

Optical rotation [a]D: -49.2 (c 0.5 , ethyl acetate); IR: 783, $1152,1580,1668,2956,3211 \mathrm{~cm}^{-1}$; ${ }^{1} \mathrm{H}$ NMR $(300 \mathrm{MHz}$, $\left.\mathrm{CDCl}_{3}\right): \delta 7.20-7.75(\mathrm{~m}, 4 \mathrm{H}), 6.43(\mathrm{~m}, 1 \mathrm{H}), 5.79(\mathrm{~m}, 1 \mathrm{H}), 5.35$ $(\mathrm{s}, 1 \mathrm{H}), 4.92(\mathrm{~s}, 1 \mathrm{H}), 3.89\left(\mathrm{~s}, 3 \mathrm{H}, \mathrm{OCH}_{3}\right), 2.32(\mathrm{~s}, 1 \mathrm{H}, \mathrm{OH})$; ${ }^{13} \mathrm{C}-\mathrm{NMR}\left(75 \mathrm{MHz}, \mathrm{CDCl}_{3}\right): \delta 56.21,76.70,110.24,114.76$, $121.89,123.39,130.39,137.95,145.28,156.31,192.66$; MS: m/z 208.16 expected and m/z 209.90 obtained (M-); HPLC: $100 \%$ ee. [Determined by chiral-pack OD-H $(250 \times 4.6 \mathrm{~mm}) 5 \mu \mathrm{m}$, mobile phase: $\mathrm{n}$-Hexane: Ethanol: Diethylamine (95:5:0.1), Flow rate $1.0 \mathrm{~mL} / \mathrm{min}, X=280 \mathrm{~nm}$; $t R$ (major) $=10.48 \mathrm{~min}$, run time $=30 \mathrm{~min}$, column temperature $=$ Ambient $]$.

\section{Conclusion}

We have developed a new facile method for asymmetric synthesis via the Baylis-Hillman reaction. The reaction was studied using various organocatalysts $\mathbf{3 a}-\mathbf{3} \mathbf{c}$. The organocatalyst (S)-N-(2,4-dinitrophenyl)pyrrolidine2-carboxamide (3b) proved to be the best organocatalyst in ethanol to get corresponding products with excellent yield and with excellent ee. The method was studied for a broad range of aromatic aldehydes. The yields of products for aromatic aldehydes were consistently high regardless of the type of substituent on the aromatic ring. Mild reaction conditions and high yields with excellent stereoselectivity with a wide range of substrates are some striking features of the reaction.

Acknowledgements We acknowledge, Dr. Smt. S. S. Kadam, Principal and Dr. B. C. Khade, Head Department of Chemistry, Dnyanopasak College, Parbhani for providing necessary facilities.

\section{Compliance with ethical standards}

Conflict of interest The authors declare that they have no conflict of interest.

\section{References}

1. Basavaiah D, Reddy BS, Badsara SS (2010) Recent contributions from the Baylis-Hillman reaction to organic chemistry. Chem Rev 29:5447

2. Pellissier H (2017) Recent developments in the asymmetric organocatalytic Morita-Baylis-Hillman reaction. Tetrahedron 73:2831

3. Ma GN, Jiang J-J, Shi M, Wei Y (2009) Recent extensions of the Morita-Baylis-Hillman reaction. Chem. Commun. 37:5496 
4. Basavaiah D, Veeraraghavaiah G (2012) The Baylis-Hillman reaction: a novel concept for creativity in chemistry. Chem Soc Rev 41:68

5. Singh V, Batra S (2008) Advances in the Baylis-Hillman reaction-assisted synthesis of cyclic frameworks. Tetrahedron 64:4511

6. Yu C, Hu L (2002) Successful Baylis-Hillman reaction of acrylamide with aromatic aldehydes. J Org Chem 67:219

7. Sohtome Y, Tanatani A, Hashimoto Y, Nagasawa K (2004) Development of bis-thiourea-type organocatalyst for asymmetric Baylis-Hillman reaction. Tetrahedron Lett 45:5589

8. Ballini R, Barboni L, Bosica G, Fiorini D, Mignini E, Palmieri A (2004) Fast diastereoselective Baylis-Hillman reaction by nitroalkenes: synthesis of di-and triene derivatives. Tetrahedron 60:4995

9. Hayase T, Shibata T, Soai K, Wakasuki Y (1998) Catalytic Asymmetric Baylis-Hillman Reactions and Surroundings. Chem Commun 2533-2534

10. Yu C, Liu B, Hu L (2001) Efficient Baylis-Hillman reaction using stoichiometric base catalyst and an aqueous medium. J Org Chem 66:5413

11. Luo S, Zhang B, He J, Janczuk A, Wang PG, Cheng J (2002) Aqueous Baylis-Hillman reactions of cyclopent-2-enone using imidazole as catalyst. Tetrahedron Lett 43:7369

12. Patra A, Batra S, Joshi BS, Roy R, Kundu B, Bhaduri AP (2002) TiCl4-Promoted Baylis-Hillman Reactions of Substituted 5-Isoxazolecarboxaldehydes with Cycloalkenones1. J Org Chem 67:5783

13. Pei W, Wei H, Li G (2002) The Baylis-Hillman condensation of $a, \beta$-conjugate cycloketones with aldehydes using diethylaluminum iodide alone as the promoter. Chem Commun 20:2412

14. Kinoshita $\mathrm{H}$, Osamura $\mathrm{T}$, Kinoshita $\mathrm{S}$, Iwamura $\mathrm{T}$, Watanabe $\mathrm{S}$, Kataoka T, Tanabe G, Muraoka O (2003) Chalcogeno-MoritaBaylis-Hillman reaction of enones with acetals: simple a-alkoxyalkylation of enones. J Org Chem 68:7532
15. Luo S, Mi X, Wang PG, Cheng JP (2004) The azoles: effective catalysts for Baylis-Hillman reaction in basic water solution. Tetrahedron Lett 45:5171

16. Hayashi Y, Okado K, Ashimine I, Shoji M (2002) The Baylis-Hillman reaction under high pressure induced by water-freezing. Tetrahedron Lett 43:8683

17. Kundu MK, Mukherjee SB, Balu N, Padmakumar R, Bhat SV (1994) Synlett 444

18. Coelho F, Almeida WP, Veronese D, Mateus CR, Silva Lopes EC, Rossi RC, Silveira GPC, Pavam CH (2002) Ultrasound in BaylisHillman reactions with aliphatic and aromatic aldehydes: scope and limitations. Tetrahedron 58:7437

19. Luo S, Wang PG, Cheng J (2004) Remarkable rate acceleration of imidazole-promoted Baylis-Hillman reaction involving cyclic enones in basic water solution. J Org Chem 69:555

20. Kumar A, Pawar SS (2003) Salt effects on the Baylis-Hillman reaction. Tetrahedron 59:5019

21. Thorat PB, Goswami SV, Khade BC, Bhusare SR (2012) Organocatalyzed Baylis-Hillman reaction: an enantioselective approach. Tetrahedron Asymmetry 23:1320

22. Thorat PB, Goswami SV, Khade BC, Bhusare SR (2012) Synthesis and application of proline based organocatalyst for highly enantioselective aldol reaction by hydrogen bonding. Tetrahedron Lett. 53:6083

23. Pendalwar SS, Chakrawar AV, Bhusare SR (2018) Enantioselective organocatalytic synthesis of the chiral chromenes by domino oxa-Michael-aldol reaction. Chin Chem Lett 29:942

Publisher's Note Springer Nature remains neutral with regard to jurisdictional claims in published maps and institutional affiliations. 